\title{
Controle de temperatura do concreto asfáltico em restauração rodoviária: seu impacto nos índices iniciais de irregularidade longitudinal do pavimento
}

\author{
Asphalt concrete temperature control in road reabilitation: its impact on \\ initial pavement roughness
}

\author{
Débora Raquel Pavi ${ }^{1}$, Deividi da Silva Pereira ${ }^{2}$, Lucas Dotto Bueno ${ }^{3}$, Luciano Pivoto Specht ${ }^{4}$, \\ Fernando Zucchi ${ }^{5}$, Rogério Cattelan Antocheves ${ }^{6}$ \\ ${ }^{1}$ Secretaria de Estado da Infraestrutura e Mobilidade de Santa Catarina, Santa Catarina - Brasil, deborapavi@sie.sc.gov.br \\ 2Universidade Federal de Santa Maria, Rio Grande do Sul - Brasil, dsp@ufsm.br \\ 3Universidade Federal de Santa Maria, Rio Grande do Sul - Brasil, lucas.bueno@ufsm.br \\ 4Universidade Federal de Santa Maria, Rio Grande do Sul - Brasil, luspecht@ufsm.br \\ 5Universidade Federal de Santa Maria, Rio Grande do Sul - Brasil, fernando.zucchi@ufsm.br \\ 6Universidade Federal de Santa Maria, Rio Grande do Sul - Brasil, rogerio@ufsm.br
}

\section{Recebido:}

21 de maio de 2020

Aceito para publicação:

26 de setembro de 2020

Publicado:

5 de outubro 2021

Editor de área:

Francisco Thiago Aragão

\section{Palavras-chave:}

Irregularidade longitudinal.

Processo construtivo.

Custos operacionais.

Keywords:

Roughness.

Constructive process.

Operating costs.

DOI:10.14295/transportes.v29i4.2381

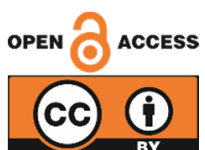

\section{RESUMO}

A irregularidade do pavimento está relacionada à percepção de conforto do usuário. Logo, sua quantificação é fundamental, inclusive na fase executiva, para mitigar seus impactos no desempenho dos pavimentos. Neste contexto, este trabalho objetivou monitorar a irregularidade longitudinal antes e após a execução de uma restauração rodoviária, onde foi avaliada a redução efetiva do IRI, e identificadas as singularidades construtivas que impactaram neste índice, a partir do acompanhamento detalhado do processo executivo, com ênfase no monitoramento da temperatura do CA aplicado com câmera termográfica. Durante este acompanhamento, foram identificadas algumas situações extraordinárias determinantes para os picos de IRI, destacando-se a distribuição irregular de massa pela vibroacabadora; acabamento manual da superfície; execução incorreta das juntas transversais; e os diferenciais térmicos nos panos de execução. As análises a partir do HDM-4, relacionando valores de IRI com os custos operacionais dos usuários, indicaram que as falhas construtivas observadas afetaram sensivelmente seus custos.

\begin{abstract}
The roughness of the pavement reflects the user's perception of trafficability and comfort. Therefore, its quantification is essential, including in the executive phase, to mitigate its impacts on pavement performance. In this context, this paper objective to monitor the roughness before and after the execution of a road restoration, where the effective reduction of the IRI was evaluated, and identified the constructive singularities that impacted this index, from the detailed monitoring of the executive process, with emphasis on temperature monitoring asphalt concrete applied with thermographic camera. During this follow-up, some extraordinary situations that determined the peaks of IRI were identified, standing out the irregular distribution of mass by the paver; manual surface finishing; incorrect execution of the transversal joints; and the thermal differentials in the execution places. The analyzes based on the HDM-4, relating IRI values to the users' operating costs, indicated that the constructive failures observed significantly affected their costs.
\end{abstract}

\section{INTRODUÇÃO}

As rodovias em boas condições são fundamentais para o desenvolvimento de um país, pois promovem ganhos na eficiência logística, diminuição de custos operacionais do transporte 
redução da poluição e o aumento do conforto e da segurança aos usuários (Dnit, 2006 e Barella, 2008).

No entanto, para manter uma rodovia em bom estado, são necessárias atividades contínuas de monitoramento e de manutenção da via, desde o início de sua operação e ao longo de toda sua vida útil. Segundo Soncim et al (2013), os levantamentos de informações sobre a situação da superfície e da estrutura do pavimento são formas eficazes de gerir a malha rodoviária, servindo de apoio e auxiliando na tomada de decisões referentes ao momento da aplicação de recursos na manutenção da via. Com uso destas informações, é possível otimizar os recursos disponíveis e elaborar estratégias de intervenções, tal como preconiza a gerência de pavimentos (Hass et al, 1994).

Para identificação de gatilhos que apontam a necessidade de intervenção, é fundamental que os sistemas de gerência de pavimentos possibilitem a qualificação da malha através de um indicador, tal como a irregularidade longitudinal, parâmetro que tem elevada influência na percepção da qualidade da via por parte do usuário, e pode ser considerado o mais importante indicativo de desempenho funcional dos pavimentos (Hass et al, 1994). 0 índice internacional designado para a medida da irregularidade é o International Roughness Index (IRI). Esse índice estatístico, expresso em $\mathrm{m} / \mathrm{km}$ ou $\mathrm{mm} / \mathrm{m}$, quantifica os desvios do pavimento em relação a uma superfície plana de referência.

0 parâmetro de irregularidade longitudinal estabelece uma relação direta entre as características funcionais de operação dos veículos e o conforto ao rolamento percebido pelo usuário da rodovia, implicando diretamente no aumento dos custos de transporte, devido ao acréscimo no consumo de combustível e despesas relacionadas à manutenção dos veículos (Sayers e Karamihas, 1998; Barella, 2008). Bueno (2019) ainda destaca a importância da irregularidade inicial, obtida após o final do processo construtivo, na evolução deste parâmetro funcional ao longo da vida útil da rodovia.

Lerch (2002) e Nakahara (2005) apontam que a irregularidade longitudinal pode ser resultado de diversos fatores, entre eles estão as técnicas construtivas adotadas que incorrem em algumas variações do perfil da rodovia. Estudos realizados pelo Departamento de Transportes de Washington (2000) e por Lavaud (2011) enfatizam a importância de cuidados executivos e controles durante a execução para obtenção de baixos valores de irregularidade longitudinal inicial. Distribuição regular e contínua da vibroacabadora, temperatura adequada para a compactação, entre outros fatores, encontram-se entre os principais aspectos de influência nos resultados de IRI.

Além de afetar o conforto e segurança dos ocupantes dos veículos, a irregularidade longitudinal compromete a vida útil do pavimento, uma vez que o efeito dinâmico causado pelos veículos comerciais que trafegam sobre a via amplifica os esforços impostos à estrutura quando a irregularidade longitudinal é elevada, acelerando a deterioração da estrutura (Bisconsini et al, 2015). Este processo se reflete em custos adicionais para os gestores das rodovias, devido às recorrentes intervenções que precisam ser aplicadas aos pavimentos, de modo a manter a irregularidade longitudinal em níveis aceitáveis de acordo com a classe da via (Sayers e Karamihas, 1998).

Em síntese, a necessidade do levantamento de dados de irregularidade longitudinal vai ao encontro das demandas de monitoramento da condição superficial para ações gerenciais, avaliação qualitativa das execuções e restaurações dos pavimentos. Pode-se observar, ainda, que indiferentemente dos objetivos necessários para mensuração do parâmetro de irregularidade, todos remetem, de alguma forma, ao fator econômico, seja esse incidente diretamente sobre os 
usuários ou aos gestores públicos e privados. Há, inclusive, fatores de pagamento aos empreiteiros ajustados conforme o nível de irregularidade imposto ao pavimento recém-executado.

0 conceito de qualidade da via, representado em função da irregularidade, é determinado conforme Manual de Restauração do DNIT (Dnit, 2006). No que se refere às rodovias pavimentadas, os valores de IRI variam desde $1,0 \mathrm{~m} / \mathrm{km}$, para pavimentos excelentes e valores superiores a 4,6 m/ km para pavimentos em condições péssimas. No entanto, cada país estabelece o seu limite de aceitabilidade, considerando suas condições particulares para diferentes classes de rodovias e critérios adotados na decisão de intervenções reparadoras em rodovias recém construídas ou restauradas (Farias e Sousa, 2002). A normatização nacional estipula o valor de 2,7 m/km (condição de pavimento "Bom", conforme Dnit, 2006) como critério para aceitação do serviço de pavimentação (restauração e implantação). Já Aashto (2008) e ANTT propõem que este mesmo valor de $2,7 \mathrm{~m} / \mathrm{km}$ seja o critério final admissível para que ocorra uma intervenção.

Objetivando otimizar os critérios de pagamento para serviços rodoviários no Brasil, Leite e Motta (2019) realizaram um estudo propondo ajuste no fator de pagamento de obras rodoviárias (FAP), levando em consideração a irregularidade longitudinal (devido à elevada percepção por parte do usuário) e parâmetros volumétricos da mistura asfáltica (teor de ligante, volume de vazios, granulometria e espessura - que incidem diretamente na durabilidade, resistência a deformação e a fadiga). Estes critérios sugeridos (IRI e parâmetros volumétricos) são de comum entendimento por inúmeras referências e recomendados por países como Estados Unidos da América (EUA), Portugal e África do Sul, que já adotam bonificação ou penalização no pagamento de obras rodoviárias. As Agências de Transportes dos EUA e a Secretaria de Transportes do México, inclusive, especificam bonificação (incentivo financeiro) para empresas que constroem rodovias com baixos índices de IRI inicial (Leite e Motta, 2019).

Neste contexto, o presente trabalho objetiva identificar fatores que contribuem para a irregularidade longitudinal por meio do acompanhamento de processo construtivo corrente em um trecho de restauração rodoviária, sem interferência sobre a prática construtiva, com ênfase especial na temperatura do concreto asfáltico aplicado na reabilitação do pavimento. Adicionalmente, procurou-se avaliar, com o auxílio do software HDM-4, os impactos das ineficiências construtivas, observadas em campo e relacionadas com a irregularidade obtida após o final do processo executivo, nos custos operacionais dos usuários com os veículos.

Sabe-se que a irregularidade longitudinal do pavimento pode ser afetada por diversos outros fatores não comtemplados por este estudo, tais como composição estrutural, qualidade dos materiais empregados, tráfego atuante e condições climáticas da localidade. Todavia, o enfoque do trabalho está no acompanhamento passivo do processo construtivo, sem proposição de alteração neste processo, observando-se, especialmente, da temperatura do concreto asfáltico empregado no revestimento, e seus efeitos na irregularidade imediatamente após a execução e no primeiro ano de serviço do pavimento restaurado.

\section{MÉTODOS E MATERIAIS}

0 delinear metodológico aplicado neste trabalho foi dividido em duas etapas: na primeira delas, foi realizado o acompanhamento executivo integral de recuperação de um trecho rodoviário, complementado pela execução dos levantamentos de irregularidade longitudinal, antes da intervenção e ao longo do primeiro ano de serviço da via. Na segunda etapa, utilizou-se do software HDM-4 para identificar os efeitos causados pelas irregularidades constatadas em campo, após o final do processo executivo, nos custos operacionais dos usuários com os 
veículos, objetivando identificar os impactos diretos das falhas construtivas nas despesas veiculares dos usuários de rodovias.

\subsection{Delimitação da área de estudo}

O segmento monitorado encontra-se na BR-392/RS, entre os municípios de Santa Maria e São Sepé, no estado do Rio Grande do Sul, entre o km 308+400 e o km 308+900. 0 trecho consiste em 500m da faixa de rolamento dos veículos que se direcionam de Santa Maria para São Sepé. Trata-se de uma importante via que serve de canal de escoamento da produção agrícola da região celeiro do RS (centro e noroeste do estado) até o Porto de Rio Grande.

O pavimento existente é composto por um subleito argilo-silte-arenoso, uma base granular (BGS) de $170 \mathrm{~mm}$ e uma camada asfáltica composta de $130 \mathrm{~mm}$ de concreto asfáltico convencional. A restauração, realizada por um contrato de manutenção do DNIT, previu a fresagem contínua de $25 \mathrm{~mm}$ da camada asfáltica existente e sobreposição de uma camada asfáltica nova, também em concreto asfáltico convencional (CA), de 30mm.

A contagem volumétrica e classificatória do tráfego no local, realizada para o desenvolvimento deste trabalho, associada aos dados disponibilizados pelo DNIT, resultou em um número anual de operações equivalentes do eixo-padrão de, NuSACE-ANUAL =6,28 x $10^{6}$ e NAASHTO-ANUAL=1,56 x $10^{6}$ segundo os fatores de equivalência de carga do United States Army Corps of Engineers (USACE) e American Association of Highway and Transportation Officials (AASHTO), respectivamente. O VDM unidirecional de veículos foi totalizado em 3.611, sendo 2.379 veículos de passeio e 1.232 veículos comerciais. Considerando o $N$ acumulado para o período de projeto de 6 anos, com taxa de crescimento de $3 \%$ ao ano, totalizou-se NusACE $=4,11 \times 10^{7}$ e $\mathrm{N}_{\text {AASHTO }}=1,02 \times 10^{7}$.

\subsection{Caracterização dos materiais}

A nova camada em CA utilizada na reabilitação da estrutura empregou CAP 50/70, com enquadramento da mistura na Faixa "C" do Dnit (031/2006- ES). Os dados de projeto do concreto asfáltico, bem como os resultados obtidos nas extrações realizadas durante os dois dias de execução estão apresentados na Tabela 1.

Tabela 1 - Características da mistura asfáltica

\begin{tabular}{llll}
\hline Características & $\begin{array}{l}\text { Dados do projeto da mistura } \\
\text { betuminosa }\end{array}$ & $\begin{array}{l}\text { Dados da extração. } \\
\text { Dia 01 - Uma amostra }\end{array}$ & $\begin{array}{l}\text { Dados da extração. } \\
\text { Dia 02 - Uma amostra }\end{array}$ \\
\hline Teor de ligante de projeto (\%) & $5,95( \pm 0,3)$ & 5,81 & 5,78 \\
Volume de Vazios (\%) & 4,07 & 3,96 & 4,01 \\
Relação Betume Vazio (R.B.V) (\%) & 76,15 & 75,85 & 76,52 \\
Estab. Marshal Corrigida kgf (75 Golpes) & 1.140 & 1.198 & 1.185 \\
Densidade Aparente ton/m 3 & 2.192 & 2.204 & 2.183 \\
Vazio Agregado Mineral (V.A.M) (\%) & 17,1 & 15,6 & 16,6 \\
Equivalente de Areia (\%) & 61,8 & 62,5 & 62,4 \\
Temperatura de compactação ( ${ }^{\circ}$ C) & 134 a 140 ${ }^{\circ}$ C & - & - \\
Faixa de Trabalho DNIT 031/2006 - ES & Faixa C & Faixa C & Faixa C \\
\hline
\end{tabular}

Não é a intenção, do presente trabalho, discutir o efeito das misturas asfálticas na irregularidade longitudinal ao longo do tempo. Bueno (2019), mediante utilização de dados de caracterização viscoelástica avançada de misturas asfálticas, identificou relação entre os indicadores de irregularidade e a qualidade do material empregado no revestimento; todavia, os resultados do autor indicam para impactos acarretados em idades mais avançadas de operação do pavimento. 
Neste trabalho, cujo acompanhamento consiste no primeiro ano de serviço da estrutura pós reabilitação, buscou-se atrelar o indicador funcional ao aspecto construtivo. Em vista disso, os dados referentes a mistura asfáltica serão utilizados apenas a título de contextualização geral do segmento estudado.

\subsection{Processo Construtivo}

A restauração foi iniciada com a fresagem parcial contínua $(25 \mathrm{~mm})$ da camada asfáltica preexistente. Após a fresagem, a superfície foi varrida com uma vassoura mecânica acoplada à Bobcat. A superfície recebeu então a pintura de ligação, que foi realizada com caneta. Após, iniciou-se a execução da nova camada de concreto asfáltico. É importante salientar que o revestimento asfáltico existente se encontrava com afundamento nas trilhas de rodas de forma leve e microfissuras que, em alguns pontos, encontravam-se interligadas, causando bombeamentos de finos para a superfície.

Destaca-se também que, no segmento experimental avaliado, não foram efetuadas correções do greide com o serviço de fresagem ou recapeamento. As espessuras de fresagem e posterior aplicação de concreto asfáltico foram contínuas, sem diferenciação geométrica ao longo da totalidade do trecho avaliado. Entende-se que a ausência de controle topográfico com nível óptico de precisão pode acarretar em situações prejudiciais ao pavimento ao longo do tempo; todavia, buscou-se trabalhar com condições operacionais corriqueiras da prática rodoviária na localidade.

A distribuição do concreto asfáltico ocorreu com o auxílio de uma vibroacabadora modelo Ciber AF 5500 de pneus. Por se tratar de uma faixa de rolamento simples, de 3,6m de largura, a abertura da vibroacabadora foi ajustada para realizar toda a cobertura da faixa. 0 material foi disposto com uma espessura de $40 \mathrm{~mm}$ (controlada por operador) para que, após o processo de compactação, a camada final restaurada apresentasse espessura final de projeto de $30 \mathrm{~mm}$.

A execução dos $500 \mathrm{~m}$ monitorados fora realizada em dois dias consecutivos, 07 e 08 de junho

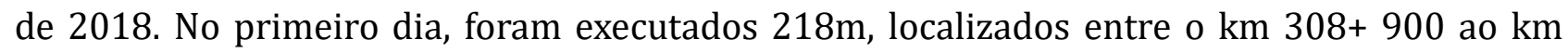
$308+682 \mathrm{~m}$, onde foram empregadas 4 cargas de concreto asfáltico. A temperatura ambiente encontrava-se em aproximadamente $18^{\circ} \mathrm{C}$.

No segundo dia, foram executados os $282 \mathrm{~m}$ restantes $-\mathrm{km} 308+682 \mathrm{~m}$ ao $\mathrm{km} \mathrm{308+400}$. A temperatura ambiente variou durante a execução, de $15^{\circ} \mathrm{C}$ à $21^{\circ} \mathrm{C}$. Neste dia, também foram empregadas 4 cargas de concreto asfáltico

0 processo de compactação realizado em ambos os dias foi o mesmo. Inicialmente, foi realizada a passagem do rolo liso (Modelo Dynapac CC 424HF), rolando em média, a 6 coberturas do pano de CA em execução. Após, o rolo pneumático (Modelo Dynapac CP 274) realizou a compactação, em média, com adicionais 12 coberturas. A pressão de inflação adotada para os pneumáticos do rolo foi de $827 \mathrm{kPa}$, desde o início da rolagem. A sequência executiva pode ser observada nas imagens da Figura 1.

Além dos controles tradicionais de temperatura, também foi utilizada uma câmera infravermelha FLIR T440, com amplitude térmica de $-20^{\circ} \mathrm{C}$ a $1200^{\circ} \mathrm{C}$. Antes da captação das imagens infravermelhas, a câmera foi configurada com os seguintes parâmetros: temperatura ambiente, emissividade (0,90 - recomendada pela literatura) e umidade relativa do ar. 0 segmento a ser avaliado foi demarcado a cada $10 \mathrm{~m}$ a fim de facilitar o registro e o acompanhamento completo dos eventos construtivos relevantes ocorridos durante a execução dos serviços de pavimentação. A apresentação detalhada deste processo está exposta em Pavi (2019). 


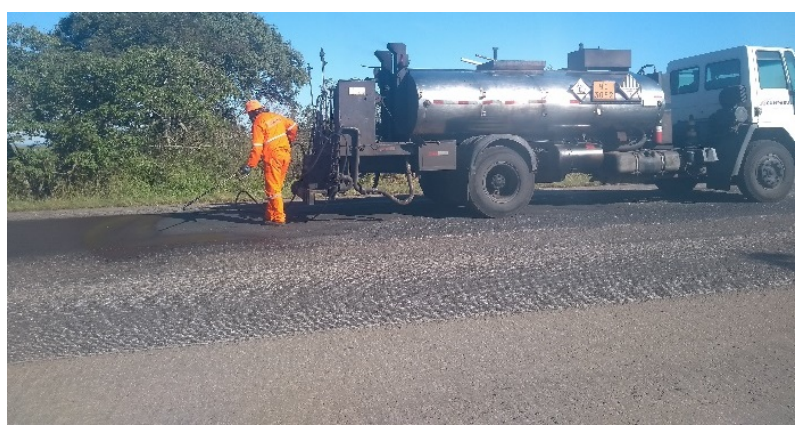

(a)

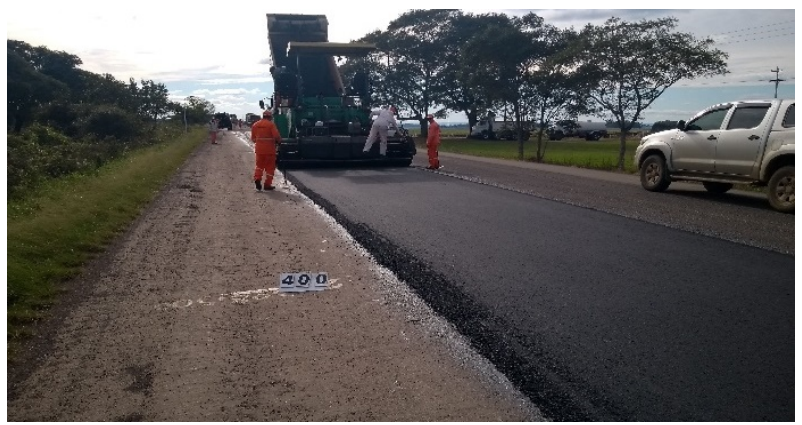

(b)

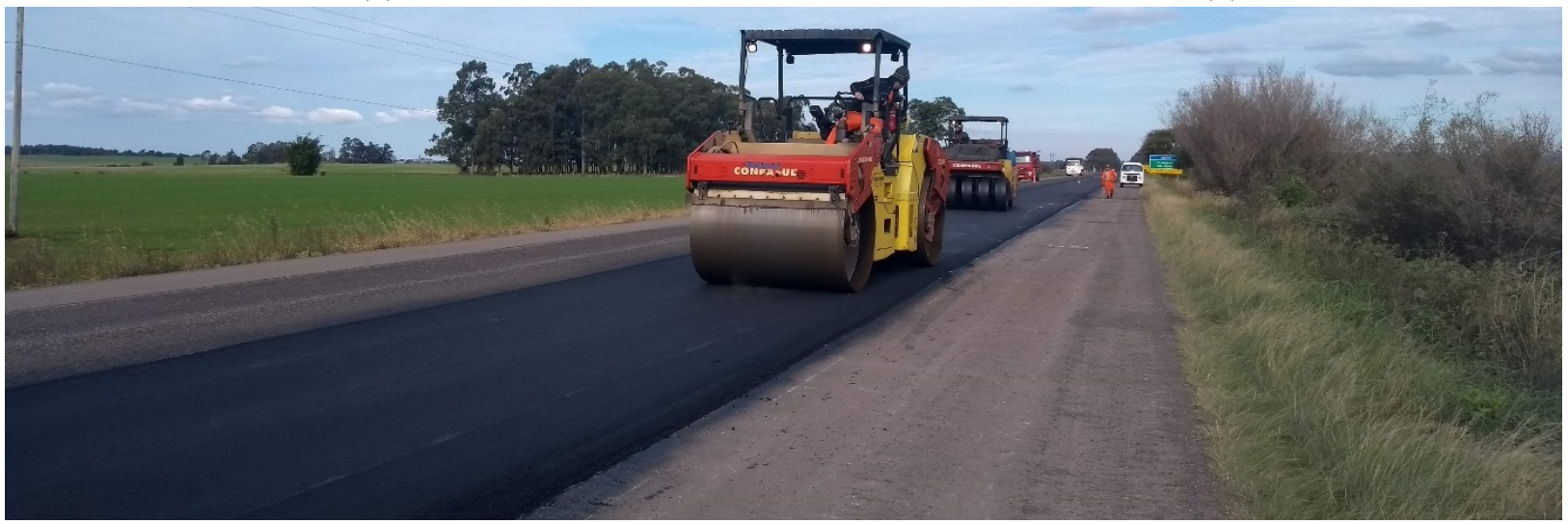

(c)

Figura 1. Sequência executiva (a) aplicação de pintura de ligação, (b) distribuição de CA pela vibroacabadora e (c) compactação inicial pelo rolo chapa seguido do rolo pneumático

\subsection{Levantamentos de Irregularidade Longitudinal do Pavimento}

Foram realizados levantamentos de irregularidade longitudinal com um Perfilômetro Inercial a Laser em cinco alinhamentos longitudinais da faixa de rolamento que iria sofrer a restauração. A saber: na borda interna, na trilha de roda interna, no meio da faixa, na trilha de roda externa e na borda externa, conforme Figura 2. Os levantamentos, agrupados de $10 \mathrm{em} 10 \mathrm{~m}$, foram realizados antes da execução da fresagem, imediatamente após a execução da restauração e ao longo do primeiro ano de uso da via. Diferentemente do que é preconizado pela norma DNERPRO 182/94, este procedimento fora adotado a fim de possibilitar uma maior precisão na avaliação deste parâmetro, bem como a relação deste com eventos singulares do processo construtivo.

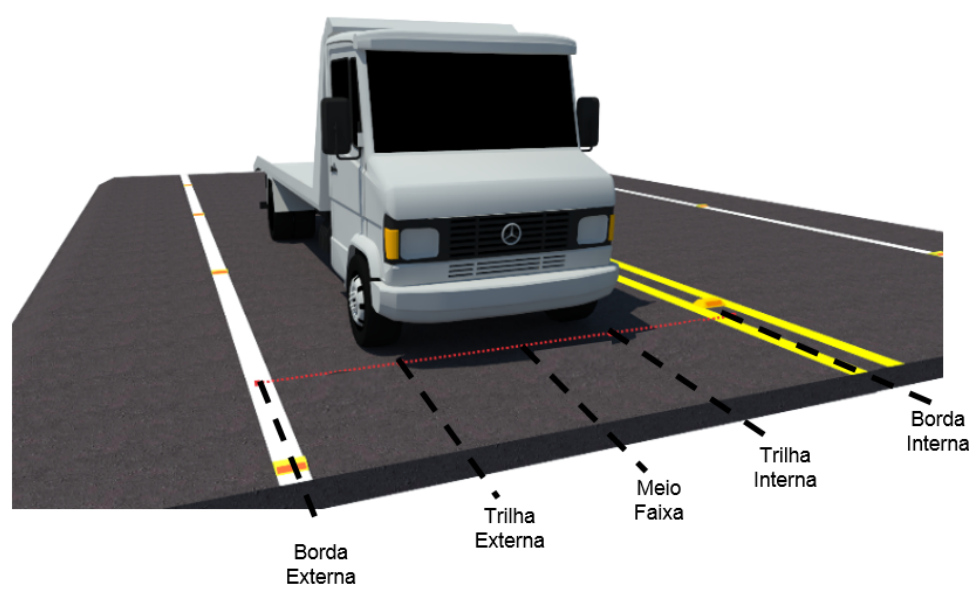

Figura 2. Pontos de levantamento de irregularidade longitudinal com Perfilômetro 


\subsection{Análise Econômica com o software HDM-4}

No intuito de relacionar a irregularidade longitudinal com os custos operacionais de usuários de rodovias, avaliações econômicas foram realizadas com o programa HDM-4, versão 2.10. Para este trabalho, foram avaliados os custos demandados aos usuários da rodovia (Road User Costs - $R U C$ ), visando verificar o impacto econômico causado pelas falhas construtivas, percebidas pela irregularidade avaliada após a reabilitação rodoviária. Neste procedimento metodológico, a composição do RUC compilou apenas os custos referentes à operação dos veículos (consumo de combustível, desgaste dos pneus, consumo de óleo lubrificante e depreciação do veículo).

O procedimento efetuado seguiu as recomendações propostas por Bueno (2019), que realizou uma calibração no modelo de progressão de irregularidade longitudinal do HDM-4 com base em resultados experimentais de trechos monitorados no Brasil. Utilizando as constantes de calibração propostas pelo autor e a base de tráfego contabilizada no presente trabalho por contagens, exposto anteriormente no item 2.1, procurou-se identificar os efeitos nos custos operacionais dos usuários com os veículos em duas distintas situações. Na primeira delas, a irregularidade inicial após o final do processo construtivo foi considerada como a média dos resultados alcançados nos subtrechos onde a irregularidade permaneceu abaixo do valor sugerido por Dnit (2006) para condição de pavimento "Bom" - 2,70m/km. Já em um segundo momento, foi selecionado o valor médio de irregularidade dos subtrechos que resultaram em IRIs acima do limite sugerido pelo Dnit.

Tabela 2 - Preços inseridos no HDM-4 para a frota de veículos

\begin{tabular}{|c|c|c|c|c|c|c|}
\hline Veículo & & VDM & Veículo Novo & Pneu & $\begin{array}{l}\text { Litro de } \\
\text { Combustivel }\end{array}$ & $\begin{array}{l}\text { Litro de } \\
\text { Óleo Lubrificante }\end{array}$ \\
\hline Moto & & 715 & $\mathrm{R} \$ 15.000$ & $\mathrm{R} \$ 250$ & $\mathrm{R} \$ 4,70$ & $\mathrm{R} \$ 25$ \\
\hline Carro de Passeio & & 5913 & $\mathrm{R} \$ 70.000$ & $R \$ 300$ & $\mathrm{R} \$ 4,70$ & $\mathrm{R} \$ 25$ \\
\hline Utilitário, pick-up, furgão & & 319 & $\mathrm{R} \$ 100.000$ & $\mathrm{R} \$ 580$ & $R \$ 3,60$ & $\mathrm{R} \$ 25$ \\
\hline Ônibus (2 eixos) & & 276 & $\mathrm{R} \$ 200.000$ & $\mathrm{R} \$ 1.300$ & $R \$ 3,60$ & $\mathrm{R} \$ 25$ \\
\hline Ônibus (3 eixos) & & 0 & -- & -- & -- & -- \\
\hline \multirow{3}{*}{ Caminhão Médio } & $2 \mathrm{C}$ & 309 & $\mathrm{R} \$ 150.000$ & $\mathrm{R} \$ 1.300$ & $R \$ 3,60$ & $\mathrm{R} \$ 25$ \\
\hline & $3 C$ & 150 & $\mathrm{R} \$ 300.000$ & $R \$ 1.300$ & $R \$ 3,60$ & $\mathrm{R} \$ 25$ \\
\hline & $4 C$ & 15 & $\mathrm{R} \$ 320.000$ & $\mathrm{R} \$ 1.300$ & $\mathrm{R} \$ 3,60$ & $\mathrm{R} \$ 25$ \\
\hline \multirow{5}{*}{ Caminhão Semi-reboque } & $2 \mathrm{~S} 1$ & 2 & $\mathrm{R} \$ 320.000$ & $\mathrm{R} \$ 1.300$ & $\mathrm{R} \$ 3,60$ & $\mathrm{R} \$ 25$ \\
\hline & $2 \mathrm{~S} 2$ & 38 & $\mathrm{R} \$ 320.000$ & $\mathrm{R} \$ 1.300$ & $R \$ 3,60$ & $\mathrm{R} \$ 25$ \\
\hline & $2 \mathrm{S3}$ & 20 & $\mathrm{R} \$ 320.000$ & $R \$ 1.300$ & $R \$ 3,60$ & $\mathrm{R} \$ 25$ \\
\hline & 2S3 Comb. & 17 & $\mathrm{R} \$ 320.000$ & $R \$ 1.300$ & $R \$ 3,60$ & $\mathrm{R} \$ 25$ \\
\hline & 353 & 52 & $\mathrm{R} \$ 320.000$ & $\mathrm{R} \$ 1.300$ & $\mathrm{R} \$ 3,60$ & $\mathrm{R} \$ 25$ \\
\hline Duplo Semi-reboque & $3 \mathrm{~S} 2 \mathrm{~S} 2$ & 18 & $\mathrm{R} \$ 370.000$ & $\mathrm{R} \$ 1.300$ & $R \$ 3,60$ & $\mathrm{R} \$ 25$ \\
\hline \multirow{4}{*}{ Caminão + reboque } & $2 \mathrm{C2}$ & 0 & -- & -- & -- & -- \\
\hline & $2 \mathrm{C} 3$ & 0 & -- & -- & -- & -- \\
\hline & $3 C 2$ & 2 & $\mathrm{R} \$ 370.000$ & $\mathrm{R} \$ 1.300$ & $R \$ 3,60$ & $\mathrm{R} \$ 25$ \\
\hline & $3 C 3$ & 6 & $\mathrm{R} \$ 370.000$ & $\mathrm{R} \$ 1.300$ & $R \$ 3,60$ & $\mathrm{R} \$ 25$ \\
\hline Treminhão & $3 \mathrm{C} 2 \mathrm{C} 2$ & 0 & -- & -- & -- & -- \\
\hline Rodotrem & $3 \mathrm{~S} 2 \mathrm{C} 4$ & 0 & -- & -- & -- & -- \\
\hline
\end{tabular}

No âmbito deste trabalho, para customização das informações referentes à frota de veículos, os preços da gasolina, óleo diesel, óleo lubrificante, valor do veículo e custo médio de um pneu foram definidos conforme expostos na Tabela 2. Para balizamento dos custos dos veículos e pneus, utilizou-se dos catálogos da Honda, Volkswagen (precificados pela Tabela FIPE - Fundação Instituto de Pesquisas Econômicas) e Goodyear (quantificados em varejo). Os valores do litro de gasolina e óleo diesel foram determinados por valores médios cobrados no estado do 
Rio Grande do Sul, tendo como referência o mês de fevereiro de 2020. 0 preço dos óleos lubrificantes foi balizado em catálogos da Shell, quantificados em varejo.

Com estas duas faixas de IRI, foram calculados os custos operacionais dos usuários com os veículos nas distintas situações, vislumbrando estimar o impacto das falhas no processo construtivo sobre os custos operacionais. As espessuras de fresagem e recapeamento seguiram a condição real empregada no trecho monitorado.

Visando obter resultados padronizados, definidos em termos de custo por $\mathrm{km}$ rodado $(\mathrm{R} \$ / \mathrm{km})$, a pista avaliada foi considerada com extensão quilométrica $(1 \mathrm{~km})$. A moeda adotada na análise econômica foi o dólar americano (US\$), convertido para reais (R\$) apenas na tabulação dos resultados gerados pelo HDM-4, por meio da cotação do dia 01/02/2020 (US\$1,00 = $\mathrm{R} \$ 4,28)$.

Para balizar o impacto econômico ao longo do tempo, os valores foram corrigidos por uma inflação média de 5,92\% ao ano, com base no índice IPCA (Índice Nacional de Preços ao Consumidor Amplo), fornecido pelo IBGE (Instituto Brasileiro de Geografia e Estatística). Para determinação deste valor médio, foram utilizadas séries históricas do IPCA brasileiro nos últimos cinco anos (2015 a 2019).

\section{RESULTADOS E ANÁLISES}

Conforme as ações descritas no delinear metodológico deste trabalho, os resultados dos levan-

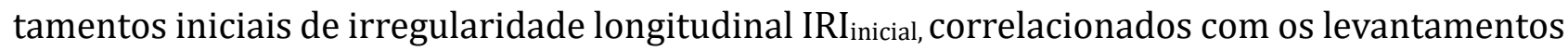
realizados antes da restauração, estão apresentados nos gráficos da Figura 3.

$\mathrm{Na}$ Figura 3, foi adicionada uma linha de valores de irregularidade longitudinal, IRI=2,70m/km, chamada de "Admissível DNIT". Este valor é balizado no critério funcional do Manual de Restauração (Dnit, 2006), para a condição de rolamento "Boa”.

Observa-se, na Figura 3, que a reconstrução da camada superficial com 30mm em concreto asfáltico corrigiu a maioria dos problemas de irregularidade registrados antes da intervenção. O IRI médio levantado antes da restauração era de $3,13 \mathrm{~m} / \mathrm{km}$, caindo para $1,9 \mathrm{~m} / \mathrm{km}$ após a intervenção, ou seja, ocorreu uma redução média de 39\% na irregularidade longitudinal. Essa redução verificada em campo é maior que a esperada por modelos de previsão, tal como de Lerch (2002) e Nakahara (2005), que previram redução média de 14\% e 18,7\% respectivamente.

No entanto, apesar da correção da grande maioria dos casos de elevado IRI, ocorreram alguns picos isolados de irregularidade longitudinal inicial, destacados na Figura 3 por círculos. Estes pontos apresentam resultados de IRI acima do valor indicado no critério funcional do Manual de Restauração (Dnit, 2006), para a condição de rolamento "Boa”.

Para melhor visualização, foram traçados diagramas da superfície (Figura 4) englobando a extensão do trecho avaliado. 0 diagrama (a) representa a condição do pavimento, em termos de IRI, antes da intervenção, enquanto que o diagrama (b) expõe a condição da superfície imediatamente após a restauração. Nos diagramas, estão em destaque (vermelho), aquelas regiões com IRI superior a 2,70m/km, conforme apresentados na Figura 4 (a) e (b).

Observa-se no diagrama de superfície da Figura 4 (a), que o pavimento antes da intervenção apresentava a maioria da área analisada (cerca de 57\%) com problemas de irregularidade (IRI $>2,70 \mathrm{~m} / \mathrm{km}$ ). A intervenção adotada reduziu significativamente essa área, caindo para cerca de $12 \%$, conforme pode ser visualizado no diagrama de superfície da Figura 4 (b). Analisando a superfície imediatamente após a restauração, verifica-se que a área mais problemática com 
relação a irregularidade longitudinal está nas proximidades da junta transversal/construtiva. Nesta área, foi possível identificar uma série de fatores que tiveram como resultado uma superfície irregular.

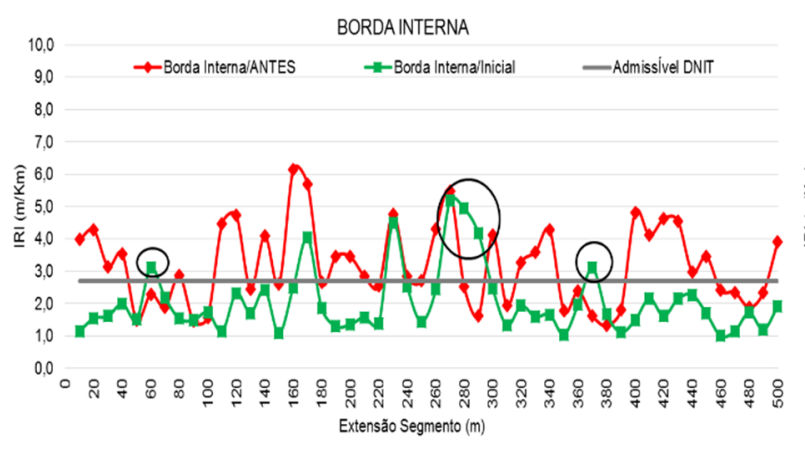

(a)

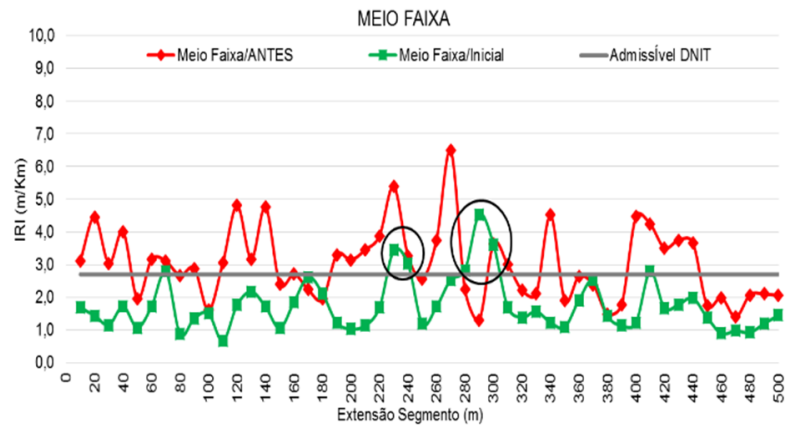

(c)

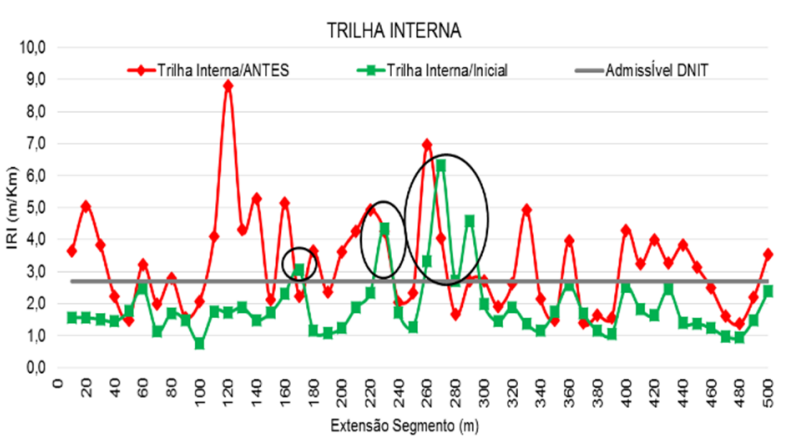

(b)

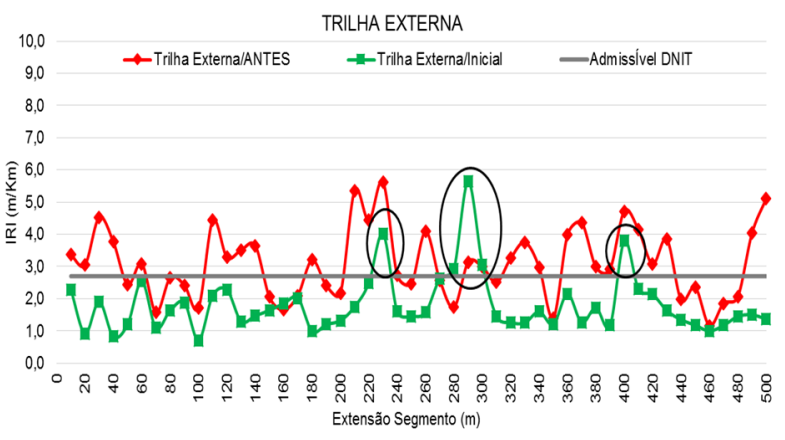

(d)

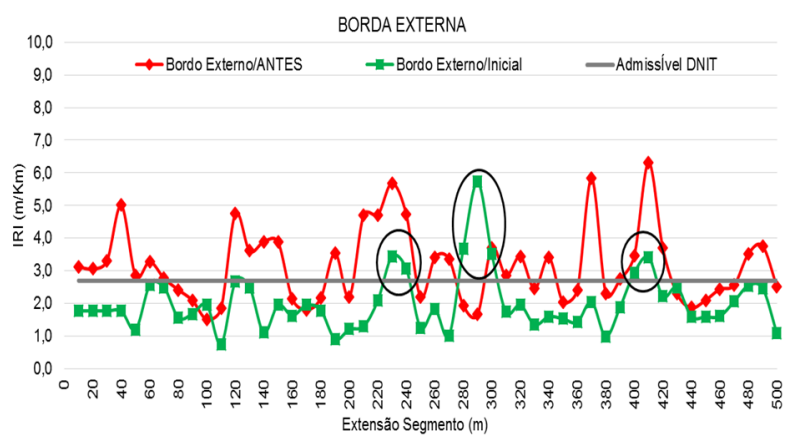

(e)

Figura 3. Irregularidade longitudinal antes e após execução de restauração: (a) borda interna; (b) trilha interna; (c) meio faixa; (d) trilha externa e (e) borda externa

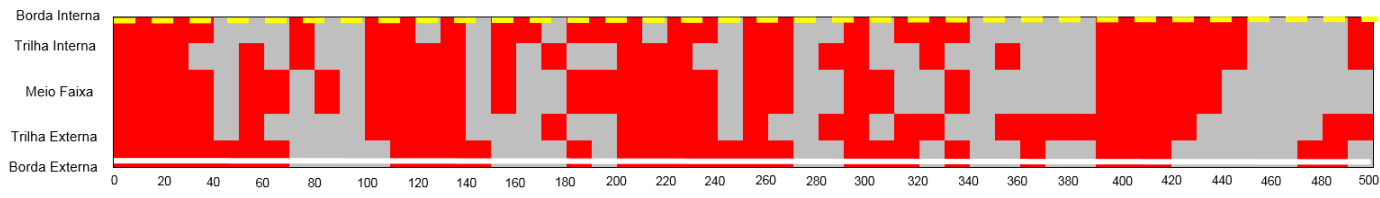

(a)

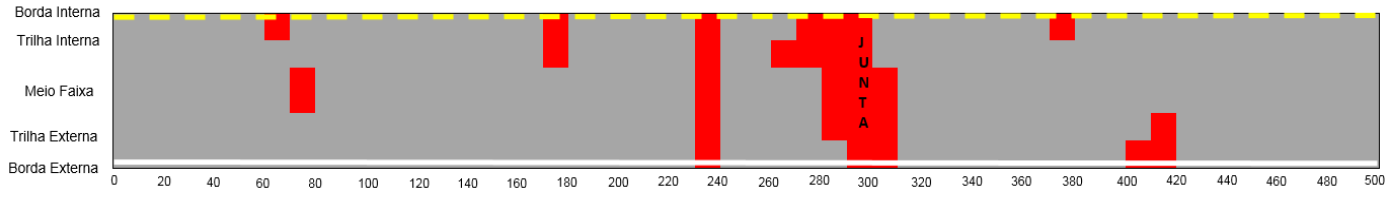

(b)

Figura 4. Comportamento da irregularidade longitudinal antes e após restauração: (a) irregularidade antes da intervenção; (b) irregularidade após intervenção 
Nas imagens termográficas da Figura 5, encontram-se os fatores identificados, sendo estes: em (a), é apresentado o pano de execução no final da jornada de trabalho do primeiro dia, sendo possível verificar elevado diferencial de temperatura. Ademais, mesmo nos pontos de maior temperatura da massa, as medidas ainda são inferiores à temperatura recomendada pelo projeto para compactação $\left(134^{\circ}\right.$ a $\left.140^{\circ} \mathrm{C}\right)$.

Em (b), além da execução de junta construtiva com massa fria, verificou-se que a vibroacabadora, por se encontrar desaquecida, apresentou problemas na distribuição do concreto asfáltico. A distribuição ocorreu de maneira irregular, conforme pode-se observar nas imagens (b) e (c). Com isso, foi necessário complementar o material asfáltico com carrinho de mão, resultando em acabamento da superfície de forma manual (com rastelo), conforme pode ser observado em (c).
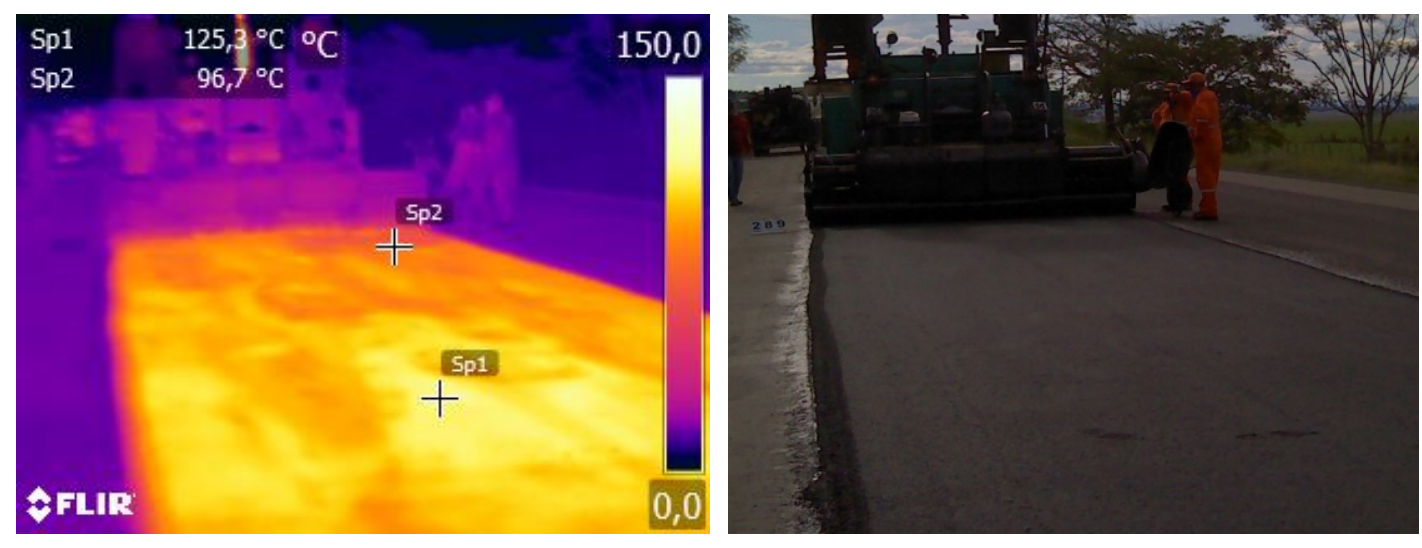

(a)

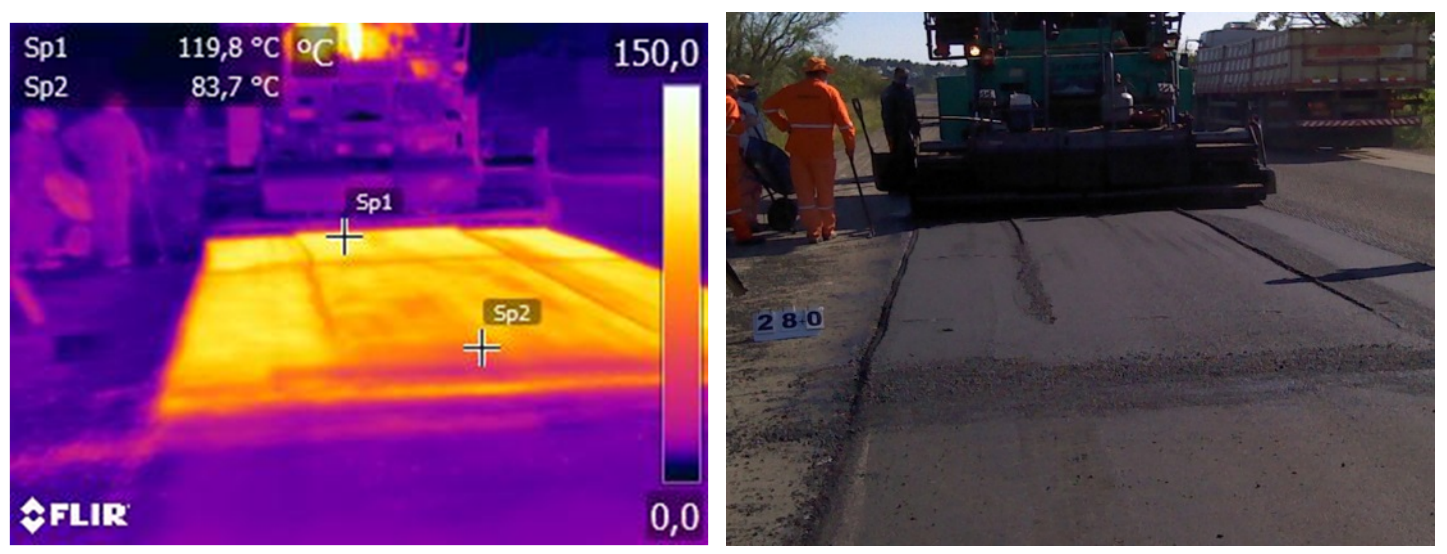

(b)
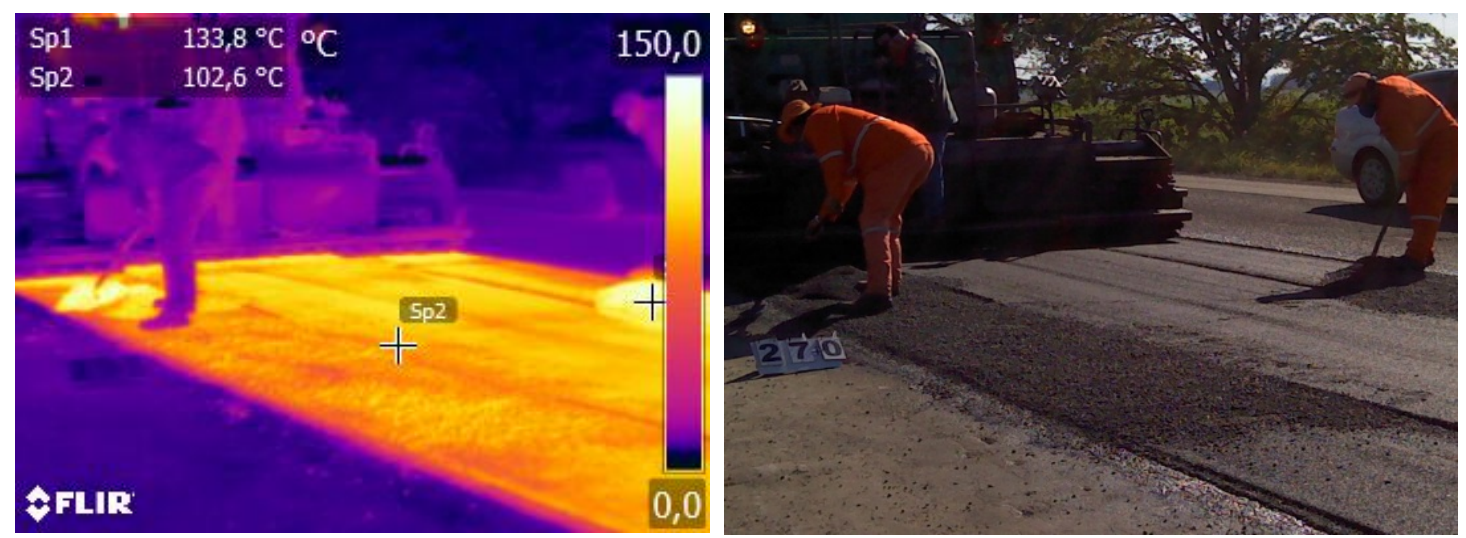

(c)

Figura 5. (a) término de jornada com temperatura do CA abaixo das recomendações; (b) execução de junta construtiva e distribuição irregular pela vibroacabadora; (c) complementação de material e acabamento manual 
Neste contexto, Lavaud (2011) infere que a irregularidade longitudinal de uma rodovia em seu período inicial está diretamente relacionada à compactação não uniforme das camadas do pavimento, em especial, devido à segregação de temperatura e do material utilizado na camada de rolamento. Ainda, o autor sustenta que os diferenciais de temperatura encontrados nas massas asfálticas em campo são, muitas vezes, superiores à $14^{\circ} \mathrm{C}$, contribuindo assim para o surgimento de falhas prematuras nos pavimentos com o conseguinte aumento da irregularidade. Lavaud (2011) enfatiza que durante a execução da respectiva camada, a acabadora deve funcionar continuamente: " $90 \%$ de todos os problemas são eliminados caso a vibroacabadora funcione a velocidade constante". Destaca-se que, no presente estudo, tanto segregação de temperatura quanto problemas na distribuição pela vibroacabadora foram observadas durante o acompanhamento de campo, possibilitando a correlação destas situações com as altas irregularidades.

Faccin et al (2015) verificou que a temperatura durante a execução do concreto asfáltico impacta nas propriedades volumétricas e mecânicas da mistura. Quando as misturas são compactadas a temperaturas abaixo da recomendação, tendem a apresentar menor densidade e mais vazios, facilitando a entrada de água na massa, contribuindo para uma redução das propriedades mecânicas. 0 módulo de resiliência e a resistência à tração tendem a diminuir para menores temperaturas de compactação.

Outro ponto identificado com elevado índice de irregularidade, IRI, localiza-se nas proximidades da borda interna do ponto 60. Nesta área, conforme destacado na Figura 6, a temperatura da massa asfáltica antes da compactação se encontrava significativamente abaixo $\left(105^{\circ} \mathrm{C}\right)$ daquela recomendada em projeto (entre $134^{\circ}$ e $140^{\circ} \mathrm{C}$ ). Observa-se ainda, na Figura 6, que a superfície irregular coincide justamente com a área "fria".

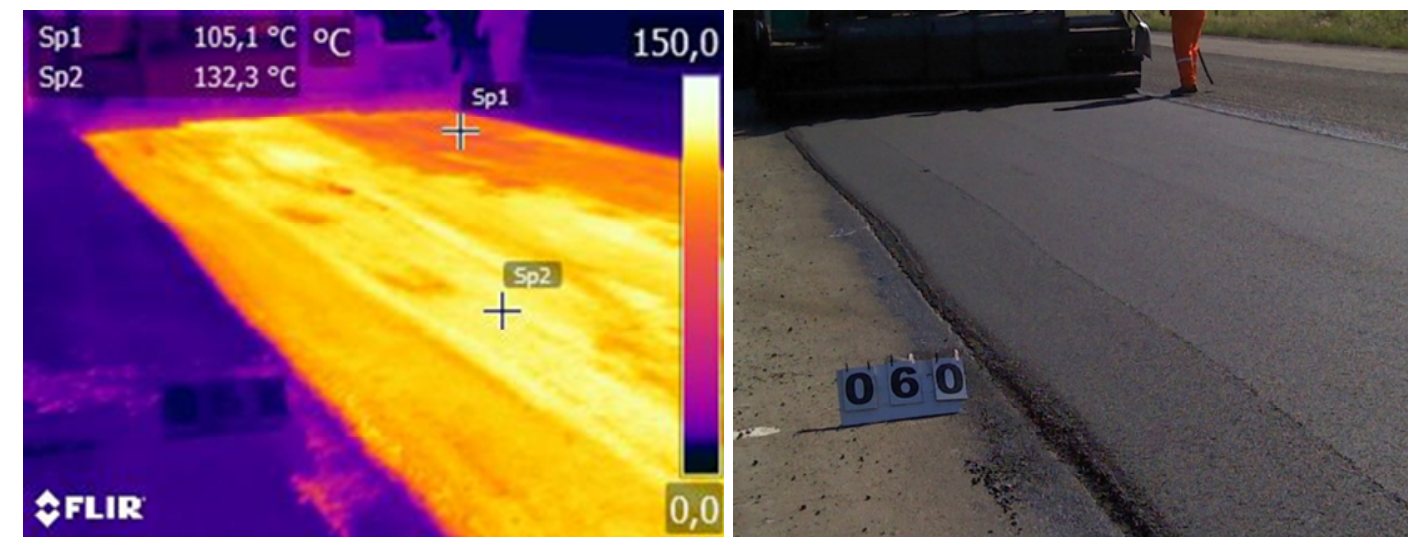

Figura 6. Temperatura excessivamente baixa para a compactação do concreto asfáltico

Logo, entende-se que a baixa temperatura do CA interferiu, significativamente, na qualidade do processo de compactação, uma vez que o ligante asfáltico, apresentando menor viscosidade que o recomendado para o processo de densificação do concreto asfáltico, dificulta o procedimento de compactação, gerando níveis de densificações distintos, implicando na imposição de "bumpings" (superfícies irregulares) no pavimento, que foram plenamente capturados pelos levantamentos conduzidos pelo perfilômetro inercial.

Corroborando, em estudo realizado pelo Departamento de Transportes de Washington (Wsdot, 2000), verificou-se que, quando diferenciais de temperatura maiores que 14\% $\mathrm{C}$ parecem na mistura asfáltica colocada pela acabadora, a porcentagem de vazios aumenta 
aproximadamente em $2 \%$. Segundo este estudo, para cada $1 \%$ de incremento na porcentagem de volume de vazios, há uma redução de aproximadamente $10 \%$ na vida do pavimento, impactando na irregularidade do pavimento - situação observada também no presente estudo.

Outro aspecto levantado no decorrer do desenvolvimento deste trabalho foi a não utilização do controle eletrônico de greide na vibroacabadora durante a execução do recapeamento. No âmbito deste estudo, não foi possível avaliar se esta prática construtiva teria efeitos diretos na irregularidade longitudinal medida após o final do processo construtivo; todavia, a hipótese de que a qualidade do equipamento e sua regulagem podem contribuir na condição do IRI medido após o final do processo construtivo não pode ser totalmente descartada.

\subsection{Continuidade do Monitoramento da Via Restaurada}

A superfície do pavimento avaliado foi monitorada ao longo dos primeiros 12 meses em serviço, compreendendo um número de operações equivalentes do eixo-padrão de NUSACE=6,28 x106. Mediante análise dos resultados, não foram observados acréscimos significativos nos valores médios de irregularidade longitudinal obtidos inicialmente, conforme pode ser observado na Tabela 3.

Tabela 3 - Valores médios de irregularidade longitudinal ao longo do primeiro ano

\begin{tabular}{|c|c|c|c|c|c|c|c|c|}
\hline Linha de Medição & $\begin{array}{l}\text { IRI antes } \\
\text { intervenção } \\
(\mathrm{m} / \mathrm{km})\end{array}$ & $\begin{array}{l}\sigma \text { IRI } \\
\text { antes }\end{array}$ & $\begin{array}{l}\text { IRI após } \\
\text { intervenção } \\
(\mathrm{m} / \mathrm{km})\end{array}$ & $\begin{array}{l}\sigma \mid R I \\
\text { após }\end{array}$ & $\begin{array}{l}\text { IRI } 180 \text { dias } \\
(\mathrm{m} / \mathrm{km})\end{array}$ & $\begin{array}{l}\sigma \text { IRI } \\
180\end{array}$ & $\begin{array}{l}\text { IRI } 360 \text { dias } \\
(\mathrm{m} / \mathrm{km})\end{array}$ & $\begin{array}{l}\sigma \text { IRI } \\
360\end{array}$ \\
\hline Borda Interna & 3,19 & 1,22 & 2,04 & 0,99 & 2,20 & 1,09 & 2,18 & 1,02 \\
\hline Trilha Interna & 3,20 & 1,50 & 1,91 & 1,00 & 2,06 & 1,04 & 2,15 & 1,20 \\
\hline Meio Faixa & 3,01 & 1,11 & 1,75 & 0,79 & 1,83 & 0,84 & 1,84 & 0,88 \\
\hline Trilha Externa & 3,09 & 1,07 & 1,80 & 0,89 & 1,90 & 0,87 & 1,91 & 0,84 \\
\hline Borda Externa & 3,15 & 1,14 & 2,01 & 0,88 & 2,23 & 1,01 & 2,21 & 0,97 \\
\hline Média $(\mathrm{m} / \mathrm{km})$ & 3,13 & 1,21 & 1,90 & 0,91 & 2,04 & 0,97 & 2,06 & 0,98 \\
\hline
\end{tabular}
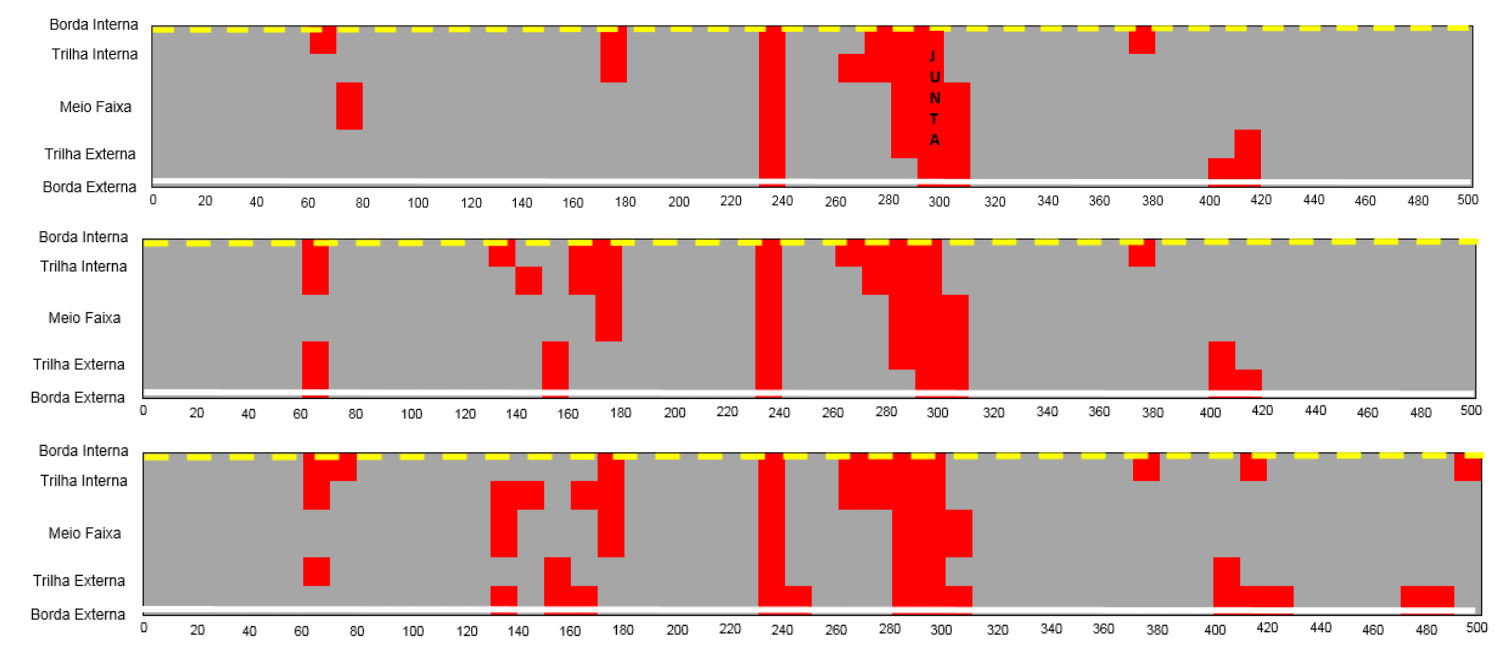

Legenda:

Figura 7. Superfície monitorada ao longo dos primeiros 360 dias: (a) irregularidade longitudinal inicial - após restauração; (b) irregularidade longitudinal 180 dias após restauração; (c) irregularidade longitudinal 360 dias após restauração

Complementarmente, analisou-se a superfície e verificou-se o surgimento de pontos com IRI $>2,70 \mathrm{~m} / \mathrm{km}$ e ocorrência de ampliação das áreas que já apresentaram problemas de irregularidade inicialmente, logo após a restauração. Os diagramas que demonstram essa 
situação estão apresentados na Figura 7 em que se observa em (a) área com problemas de irregularidade em aproximadamente $11,60 \%$, aumentando para $14,80 \%$ aos 180 dias e chegando aos $18,80 \%$ de área com valores de irregularidade acima do critério nacional após 360 dias da intervenção.

A partir de tal constatação, voltou-se a campo para a realização de uma avaliação visual e determinação do IGG da superfície conforme Norma DNIT 006/2003 PRO. Em campo, foi verificado o estágio inicial de defeitos na superfície, sendo os pontos mais evoluídos justamente coincidentes com as áreas onde ocorreram problemas executivos, conforme pode ser observado nas Figuras 8 e 9. 0 IGG avaliado após o primeiro ano em serviço foi quantificado em 52, conceituando o pavimento com em condição "Regular" ( $40<\mathrm{IGG} \leq 80)$.

Na imagem da Figura 8 (b), está demarcada a área onde ocorreu o problema na vibroacabadora, conforme descrito no item 3. Este segmento demandou complemento de material e acabamento realizado de forma manual, ocasionando segregação do material. Nas proximidades da junta fria - construtiva, observou-se, além da segregação de material, alguns arrancamentos de partículas devido à ação do tráfego e da água. Este segmento coincide com os elevados diferenciais de temperatura no pano de execução e com massa do concreto asfáltico fria (significativamente inferior à recomendação do projeto para a compactação) conforme pode ser observada na Figura 8 (a). A massa de CA fria impossibilitou a compactação adequada da camada que, como consequência, causou uma densificação desuniforme (imprimindo bumpings, inicialmente) e, em alguns pontos específicos, um volume de vazios provavelmente maior que o especificado para a massa aplicada (4\%), fazendo com que a ação do tráfego e os agentes climáticos provocassem o arrancamento das partículas superficiais devido à elevada porosidade da parcela superficial da mistura asfáltica.

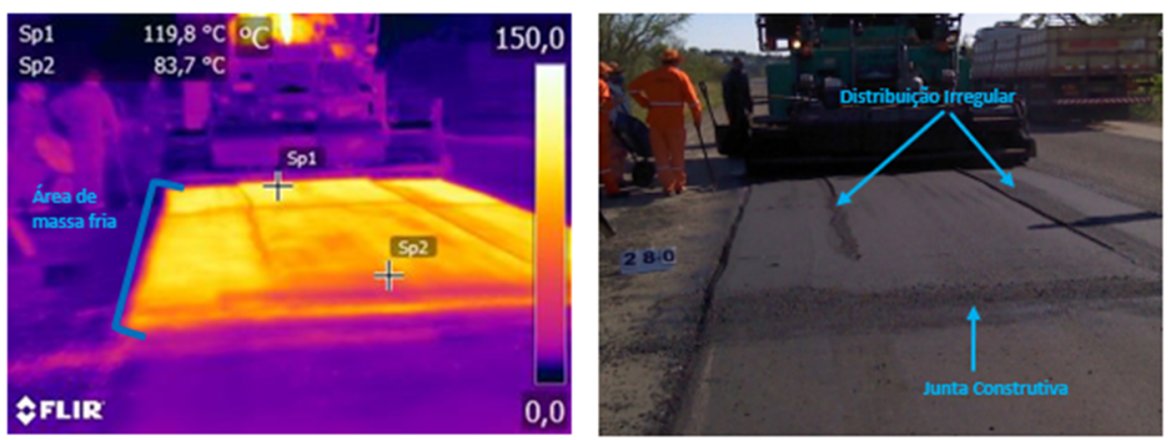

(a)

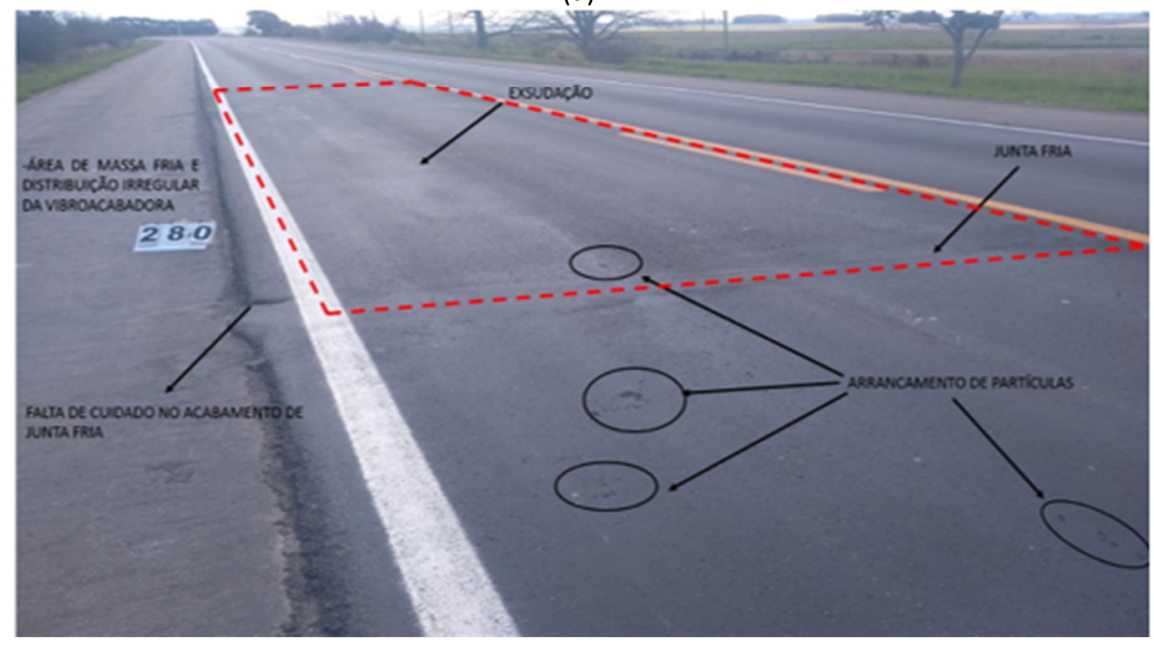

(b)

Figura 8. (a) Problemas identificados na execução e (b) defeitos em fase inicial aos 360 dias no Trecho da BR-392 
Na Figura 9 também é possível verificar o arrancamento das partículas superficiais. Essa região coincide com o início dos trabalhos do segundo dia de serviço, em que a mistura do concreto asfáltico encontrava-se, novamente, com temperatura significativamente inferior às recomendações de projeto $\left(97^{\circ} \mathrm{C}\right.$, enquanto recomendação de projeto é de 134 a $\left.140,5^{\circ} \mathrm{C}\right)$.

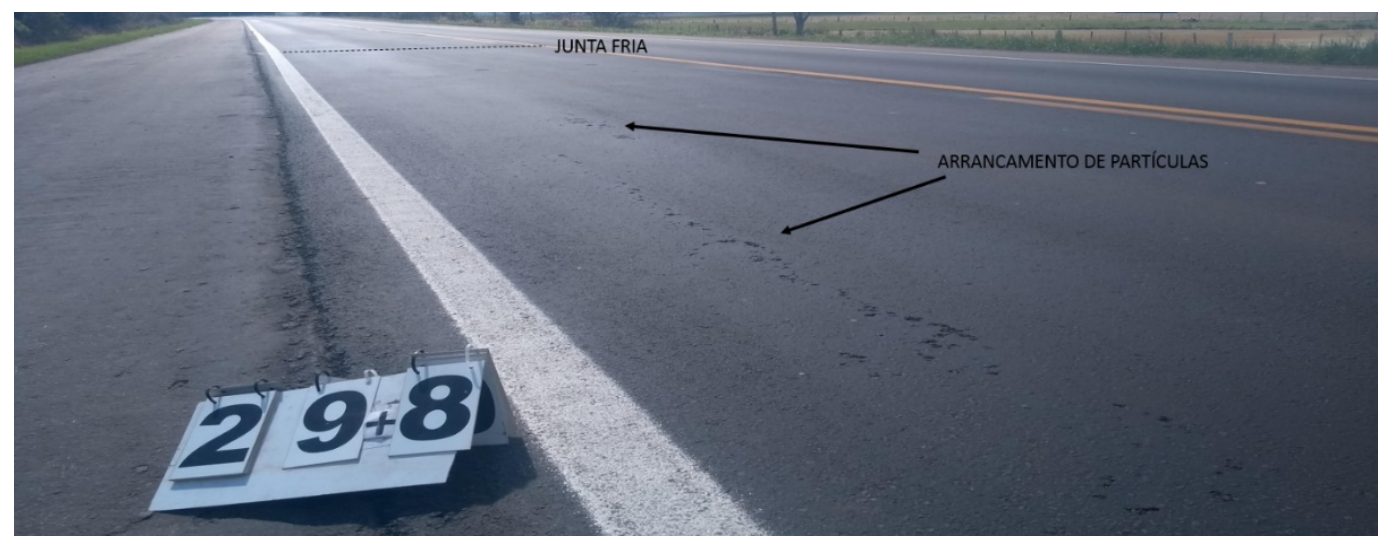

Figura 9. Defeitos superficiais em fase inicial - coincidentes com área de massa fria durante a execução no Trecho da BR-392

Logo, observou-se, no trecho restaurado, que os problemas apresentados imediatamente após a intervenção sofreram evolução ao longo do primeiro ano (360 dias). Em especial ao fenômeno de arrancamento de partículas, pode-se também atrelar sua ocorrência ao emprego de uma espessura significativamente delgada de concreto asfáltico no recapeamento da estrutura. Os 30mm atribuídos em projeto não atendem a espessura mínima sugerida pela atual proposta do Novo Método de Dimensionamento Nacional (MeDiNa), que delimita valor mínimo para revestimentos em concreto asfáltico de $50 \mathrm{~mm}$, tanto para implantação de pavimentos novos quanto para reabilitações, fato que expõe o viés de utilização de estruturas mais robustas para atendimento do tráfego rodoviário significativo, como o caso do segmento avaliado neste estudo (NuSACE $=4,11 \times 10^{7}$, para o período de projeto de 6 anos). A tendência é de que as patologias observadas aumentem sensivelmente com a ação do tráfego e do clima, possibilitando assim a entrada da água na estrutura, provocando a desintegração do revestimento e afetando a estrutura como um todo.

Fica latente, por fim, a importância de controles executivos relativamente simples, com baixo ou nenhum impacto no custo de execução, no desempenho de pavimentos restaurados, como por exemplo, a observância das faixas de temperaturas para a compactação do concreto asfáltico. Em pontos onde ocorreram problemas construtivos conforme relatado, além de apresentarem valores sensivelmente superiores de irregularidades longitudinais iniciais, estabeleceram locais frágeis no revestimento, por onde observou-se um avanço rápido de ocorrência de defeitos após a abertura ao tráfego da rodovia.

\subsection{Impacto do Controle Executivo sobre os Custos Operacionais}

Para realização da análise econômica com uso do HDM-4, conforme apresentado no item 2.5, foram considerados dois cenários distintos. No primeiro deles, a irregularidade atribuída após o final do processo construtivo foi de $1,67 \mathrm{~m} / \mathrm{km}$, valor médio obtido nos subtrechos em que não houve problemas executivos constatados durante o acompanhamento de campo, possibilitando a obtenção do índice IRI inicial (após o final do processo construtivo) abaixo do limite de 
2,70m/km, estabelecido pelo Dnit (2006) como condição da superfície do pavimento em situação "Boa”. Em um segundo momento, atribuiu-se a irregularidade de 2,82m/km após o final do processo construtivo de reabilitação, valor médio observado nos subtrechos onde a restauração do pavimento não conseguiu entregar irregularidade abaixo da recomendação efetuada pelo Dnit. A este fato, os itens precedentes atribuíram causa às falhas no processo construtivo, como fluxo intermitente e paralisação do abastecimento da vibroacabadora, incompatibilidade nas temperaturas de compactação do concreto asfáltico especificadas em projeto para a localidade, entre outros procedimentos executivos supracitados.

Com estes dois formatos de análise, verificou-se os custos operacionais dos usuários com os veículos em ambos os casos ao longo do tempo, considerando o tráfego contabilizado na localidade, crescente em uma taxa de 3,0\% ao ano, em cenários de 10, 15 e 30 anos. Considerou-se também a hipotética manutenção da irregularidade ao longo destes períodos, sem progressões acarretadas pelo fluxo de tráfego e pela degradação natural do pavimento. Destaca-se também que a análise objetivou avaliar apenas os custos operacionais dos usuários com os veículos, sem contabilizar os custos com a manutenção da rodovia ou os custos dos usuários com tempo de viagem e emissões de gases poluentes.

Com base neste formato de avaliação, pode-se dizer que, em termos médios, a manutenção das condições de irregularidade longitudinal no valor de $1,67 \mathrm{~m} / \mathrm{km}$, os usuários que trafegam pela rodovia são beneficiados com uma economia anual quantificada em aproximadamente $\mathrm{R} \$ 39.000 / \mathrm{km} / \mathrm{ano}$, em cenários de 10 anos, quando comparada à situação em que a irregularidade atribuída foi de $2,82 \mathrm{~m} / \mathrm{km}$. No cenário intermediário (15 anos), essa economia média salta para aproximados $\mathrm{R} \$ 143.000 / \mathrm{km} /$ ano. Já quando o período total de análise é compilado (30 anos), verifica-se uma economia média para o usuário de aproximadamente R\$505.000/km/ano, quando comparados os cenários apresentados neste estudo.

Estes resultados são corroborados por importantes trabalhos pré-existentes. Chesher e Harrison (1987) desenvolveram modelos paramétricos computando os custos operacionais dos veículos em unidades físicas de consumo. Os resultados mostraram que os custos operacionais aumentam a uma taxa de cerca de dois a quatro por cento por unidade IRI (m/ km), com pequenas distinções variando entre os diferentes tipos de veículos. Salienta-se também o comportamento acentuado da relação direta entre custos operacionais e irregularidade à medida que são avaliados veículos comerciais de maior porte. Paterson (1987) salienta também que, tipicamente, ao longo da gama de condições das rodovias pavimentadas, estes valores podem aumentar na ordem de $15 \%$ entre os extremos de boa (IRI em torno de $2 \mathrm{~m} / \mathrm{km}$ ) e péssima (IRI em torno de $8 \mathrm{~m} / \mathrm{km}$ ) condição de irregularidade. No presente estudo, parametrizando os resultados observados nas projeções econômicas, percebe-se que, nos cenários de mais curto prazo (10 anos), os custos operacionais dos usuários com os veículos aumentam a uma taxa de cerca de 1,4\% por unidade IRI. No período de análise intermediária (15 anos), este acréscimo sobe para 3,8\%, podendo chegar a 4,4\% nas avaliações de mais longo prazo (30 anos).

Kerali (2001), em seu trabalho que explica o papel do HDM-4 na manutenção rodoviária, constata relação direta entre os fatores econômicos e a irregularidade longitudinal, novamente com destaque para os veículos comerciais de porte elevado, caso da frota de veículos avaliada no presente estudo, com tráfego acumulado totalizado em NuSACE $=4,11 \times 10^{7}$ ao longo do período de projeto, considerado como "alto volume de tráfego" por Ceratti et al (2015).

Um apanhado geral dos componentes abordados pelos custos operacionais também foi realizado por Islam e Buttlar (2012). Os autores utilizaram o MEPDG (Mechanistic-Empirical Pavement Design Guide - Aashto, 2008) para estimar os gastos dos usuários de rodovias com 
diferentes tipos de veículos e variadas condições de irregularidade. Os resultados estimaram que os custos referentes à evolução da irregularidade, contabilizando majoritariamente combustível, desgaste dos pneus, depreciação do veículo e manutenção (mesmos elementos considerados no presente estudo) dependem significativamente do nível de irregularidade da pista.

Em vista da base literária existente e dos resultados obtidos neste trabalho, dentre as condições de contorno envolvidas na pesquisa, pode-se afirmar que, procedimentos construtivos inadequados, tais como a falta de controle da temperatura de compactação do concreto asfáltico, implicaram em importantes incrementos de custos operacionais veiculares dos usuários ao longo do tempo, conforme avaliado pelo HDM-4.

\section{CONCLUSÕES}

A partir de análise de 10 em 10m de onde ocorreram elevados índices de irregularidade longitudinal inicial, sendo estes correlacionados com imagens termográficas e completo inventário do processo construtivo, pode-se afirmar a relação entre elevados índices de IRI com diferenciais de temperatura no pano de execução, juntas construtivas (frias), distribuição irregular da vibroacabadora, falta de cuidados no acabamento durante a execução e acabamentos realizados de maneira manual. Logo, fica evidenciado o quão sensível o parâmetro de irregularidade do pavimento é frente às técnicas construtivas e falhas recorrentes durante a execução.

Verificada tal sensibilidade do parâmetro, reforça-se a importância da mensuração da irregularidade longitudinal, não apenas para auxílio na gerência dos pavimentos com o tempo, mas também como um indicativo da qualidade de execução do serviço, pois este aponta se ocorreram problemas/falhas executivas que terão influência na vida útil do pavimento.

Observou-se ainda incremento na irregularidade longitudinal após 360 dias, sendo as regiões com problemas de irregularidade coincidentes com as áreas frias durante a execução. Devido à dificuldade de compactação dessas áreas, a densidade obtida foi menor, tendo como consequência maior volume de vazios, possibilitando a entrada de água na estrutura, potencializado o surgimento precoce de defeitos superficiais.

Também foi verificado, com a simulação realizada na ferramenta HDM-4, o incremento significativo nos custos operacionais dos usuários com os veículos ao longo do tempo com o acréscimo da irregularidade longitudinal.

Por fim, entende-se que a principal contribuição deste trabalho tenha sido quantificar, objetivamente, os impactos de eventuais falhas construtivas sobre a irregularidade longitudinal do pavimento, algo que, na literatura técnica, na maioria das vezes, era apenas tratado de maneira intuitiva.

\section{AGRADECIMENTOS}

Ao DNIT- UL Santa Maria/RS, por possibilitar a realização dos levantamentos em trechos sob esta jurisdição. À equipe da Conpasul - Construção e Serviço Ltda, por facilitar a realização da pesquisa; e também à Rede de Tecnologia em Asfaltos PETROBRAS/ANP, pelo suporte financeiro essencial ao desenvolvimento desta pesquisa.

\section{REFERÊNCIAS}

Aashto (2008) Mechanistic-Empirical Pavement Design Guide (MEPDG). American Association of Highway and Transportation Officials, Washington, D.C., EUA.

Astm (2008) E1926/08 Standard Practice for Computing International Roughness Index of Roads from Longitudinal Profile Measurements. American Society of Testing and Materials, West Conshohocken, EUA.

Barella, R. M. (2008) Contribuição para a avaliação da irregularidade longitudinal de pavimentos com perfilômetros inerciais. Tese (Doutorado), Escola Politécnica da Universidade de São Paulo, São Paulo - SP.

Bueno, L. D. (2019) Contribuição para a previsão empírico-mecanicista da irregularidade longitudinal e seus desdobramentos econômicos em pavimentos asfálticos. Tese (Doutorado), Universidade Federal de Santa Maria, Santa Maria - RS. 
Bisconsini, D. R. (2016) Avaliação da Irregularidade Longitudinal dos Pavimentos com Dados Coletados por Smartphones. Dissertação (Mestrado), Escola de Engenharia de São Carlos da Universidade de São Paulo, São Carlos - SP.

Ceratti, J. A. P; Bernucci, L. B e Soares, J. B. (2015) Utilização de ligantes asfálticos em serviços de pavimentação. 1를 Edção, Abeda, Rio de Janeiro - RJ.

Chesher, A. e Harrison, R. (1987) Vehicle Operating Costs - Evidence from Developing Countries. World Bank, 392p., Washington, EUA.

Dnit (2006) Manual de Restauração de Pavimentos Asfálticos, 2ª Edição, Departamento Nacional de Infraestrutura de Transportes, Rio de Janeiro - RJ.

Dnit (2011) Manual de Gerência de Pavimentos, Publicação IPR - 745, Departamento Nacional de Infraestrutura de Transportes, Rio de Janeiro - RJ.

Dnit (2003) DNIT-PRO 006/2003: Avaliação Objetiva da Superfície de Pavimentos Flexíveis e Semi-rígidos - Procedimento - PRO, Departamento Nacional de Infraestrutura de Transportes, Rio de Janeiro - RJ.

Dner (1994) DNER-PRO 182/94: Medição da Irregularidade de Superfície de Pavimento com Sistemas Integradores IPR/USP e Maysmeter, Departamento Nacional de Infraestrutura de Transportes, Rio de Janeiro - RJ.

Echeverria, J. A. S. (2011) Avaliação do efeito de restaurações com fresagem e recapeamento nas condições funcional e estrutural de pavimentos com volume de tráfego médio. Dissertação (Mestrado), Universidade Federal do Rio Grande do Sul, Porto Alegre - RS.

Faccin, C.; Specht, L. P.; Lima, R. C. A.; Tombezi, V. M.; Tanski, M. C. e Just, M. L. (2015) Utilização de câmera infravermelha no controle executivo de misturas asfálticas a quente. Revista Estradas V.20 p.34 - 41, Porto Alegre - RS.

Farias, M. M. e Souza, R. O. (2002) Irregularidade Longitudinal e sua influência na Avaliação Funcional de Pavimentos. Encontro Nacional de Conservação Rodoviária - VI ENACOR. Brasília - BSB.

Haas, R.; Hudson, W. R. e Zaniewski, J. (1994) Modern pavement management. Krieger Publishing Company, Malabar, EUA.

Islam, S. e Butlar, W. G. (2012) Effect of pavement roughness on user costs. Transportation Research Record: Journal of the Transportation Research Board, 2285. p. 47-55. Washington, EUA. DOI: 10.3141/2285-06

Lavaud, P. (2011) Como Construir Pavimentos Asfálticos Duráveis Com Menores Custos De Manutenção. Congresso brasileiro de Rodovias e Concessões CBR\&C e 7ạ Exposição Internacional de Produtos para Rodovias - Brasvias, Anais, não paginado, Foz do Iguaçu - PR.

Lerch, R. L. (2002) Previsão de irregularidade pós-recape em rodovias do RS: ajuste do modelo HDM-4. Dissertação (Mestrado), Universidade Federal do Rio Grande do Sul, Porto Alegre - RS.

Leite, L. F. M. e Motta, L. M. G. (2019) Fator de ajuste de pagamentos em obras rodoviárias: vantagens e desvantagens e utilização no Brasil. 9 Congresso Rodoviário Português. Lisboa, Portugal.

Nakahara, S. M. (2005) Estudo do desempenho de reforços de pavimentos asfálticos em vias sujeitas a tráfego comercial pesado. Tese (Doutorado), Escola Politécnica da Universidade de São Paulo, São Paulo - SP.

Paterson, W. D. O. (1987) Road Deterioration and Maintenance Effects - Models for Planning and Management. 472 p. World Bank. Washington, EUA.

Pavi, D. R. (2019) Identificação De Fatores Construtivos Que Contribuem Para O Aumento Da Irregularidade Longitudinal A Partir Do Monitoramento De Implantação E Restauração De Trechos Rodoviários. Dissertação (Mestrado), Universidade Federal de Santa Maria, Santa Maria - RS.

Pinto, S. e Preussler, E. (2002) Pavimentação Rodoviária: conceitos fundamentais sobre pavimentos flexíveis. Copiarte, Rio de Janeiro - RJ.

Sayers, M. W. e Karamihas, S. M. (1998) The little book of profiling - Basic Information about Measuring and Interpreting Road Profiles. University of Michigan, Ann Arbour, EUA.

Soncim, S. P.; Fernandes Jr. J. L e Campos, L. E. P. (2013) Modelo de desempenho de irregularidade longitudinal desenvolvido com base em dados da rede de rodovias em tratamento superficial duplo do Estado da Bahia. Revista Transportes V. 21, N. 3, P. 22-30. DOI: 10.4237/transportes.v21i3.681. 